\title{
Managing Virtual Internships During the Covid-19 Pandemic Era: Implications for Academic Instructors and Business Leaders
}

\author{
Laura B. Klein \\ Oakland University \\ Chaunda L. Scott \\ Oakland University
}

During the beginning phase of the COVID-19 Pandemic in late March of 2020 in the United States, two academic instructors at a mid-sized, public university in the Midwest were involved in converting a traditional human resource development internship course into a virtual internship course that they would be teaching in May of 2020. This paper shares the lessons learned by the two instructors along with a summary of a relevant theoretical leadership framework that provides useful insights for academic instructors and business leaders who are or will be managing virtual academic internships in the future. This paper concludes by offering insights and recommendations for academic instructors, business leaders, and students interested in virtual internships.

Keywords: virtual internship, managing internships, triangular leadership model, internships during pandemic, global internships

\section{INTRODUCTION}

As two instructors of a traditional human resource development (HRD) internship program at a Midwest university in the summer of 2020, we were tasked with suddenly revising the program format to one that was virtual due to Covid 19. Without much experience teaching this virtually, certain challenges and opportunities arose. A challenge was that we had to convert and reinvent processes and documents to effectively manage the internship course in a virtual context given that this was a capstone course and requirement for students to graduate at the end of the semester. With not much guidance, and teaching this course remotely, we along with students and their internship supervisors, had to adjust to the new learning style quickly.

This unexpected change provided unique opportunities gained from this virtual internship experience. As instructors, along with internship students, and academic or business supervisors, we were able to advance our virtual learning knowledge and expand our online/remote communication skills while facilitating a rich and valuable internship experience for students through a virtual medium. To share some of the experiences learned by the instructors, students, and internship supervisors, we will discuss below the virtual internship criteria, triangular-leadership model, and offer recommendations for instructors, students, and business leaders interested in the practice of virtual internships learning. 


\section{VIRTUAL INTERNSHIP CRITERIA}

This section will provide an overview of the virtual internship criteria at a Midwest university. Students who were enrolled in the capstone course were required to secure a workplace site where the internship objectives could be accomplished virtually and allow them to gain experience in the area of HRD. Internship sites needed to facilitate and offer student experiences in the areas of organizational development, career development, training and development, cultural diversity, and employment systems and standards. To ensure that students have an opportunity to work at a professional level all sites were approved by staff of the HRD internship office before the student work commenced.

Students were required to work under the close supervision of a Human Resource (HR) professional (the "site supervisor") and with the additional oversight from the university HRD instructor. The HRD Internship requires a minimum of 320 hours of internship participation. These hours are completed virtually with approval of the workplace supervisor and without direct faculty supervision. Students were expected to apply their learning from their HRD course work and previous experiences. There were three mandatory virtual class meetings as well as other opportunities for each student to meet and complete tasks, experiences, and accomplishments and connect with their instructor. Students compiled an online portfolio of the work they completed from the aforementioned areas above and submitted them for final grading. The portfolio also provided students with a professional work sample that could be shared with prospective employers after the graduate.

For those students who were unable to secure an internship due to the pandemic, or had their internship cancelled prior to the beginning of the semester, the HRD internship office offered students an alternative option to complete this capstone course. These students were given the opportunity to write a scholarly research paper within the broad field of HRD. Students received support from the internship instructor, university library and writing center, and were expected to act as an independent scholars primarily by being a self-motivated researchers and authors. Students were evaluated on key milestones scheduled throughout the semester as well as engagement with the writing center and library. A key component of the scholarly research paper was the selection of an HRD-appropriate topic of interest. A non-exhaustive list of potential topics was supplied; however, students were encouraged to explore a topic in which they have a high level of interest. A research paper rubric was provided to students to highlight core criteria for the final paper.

\section{THEORETICAL FRAMEWORK: TRIANGULAR LEADERSHIP MODEL}

A useful theoretical framework that academic instructors and business leaders can draw upon when managing virtual internships is the Triangular Leadership Model by Klein (2016) as shown in Figure 1. This theoretical "triangle" framework includes: 1) transformational leadership theory, 2) authentic leadership theory, and 3) distributed leadership theory. Notably, all three theories are equally relevant and essential for leadership to demonstrate while providing leadership for virtual internships. Each of the three theories discussed offer merit and practicality when applied to understanding the leadership opportunities for success and managing student needs while engaged in the internship role.

In Klein's (2016) dissertation entitled: Understanding the Experiences of Non-traditional University Leadership in Higher Education: A Qualitative Study Using a Triangular Theoretical Approach, the transformational leadership theory was examined. This theory's impact on organizational performance has garnered attention from researchers and leaders who hope to improve institutional and organizational success. It also has developed the substance, depth, and clarity to view the phenomenon of virtual internship leaders. Additionally, authentic leadership theory provides the contemporary approach to understanding the aspects of leadership needed to survive in today's higher education and business environments. Distributed leadership recognizes in today's workplace environment, the effort to lead an organization occurs at many different levels and in many cases outside of formal leadership roles. Successful academic and business leaders managing virtual internships will possess the ability to not only understand the importance of each leadership theory, but the ability to exhibit transformational, authentic, and distributed 
leadership characteristics to meet the demands of internship students in the virtual environment. Through the lenses of transformational, authentic, and distributed leadership theories, the realistic, current, and transforming nature of virtual internship leadership roles can be interpreted.

\section{FIGURE 1}

\section{THEORETICAL TRIANGULAR LEADERSHIP MODEL}

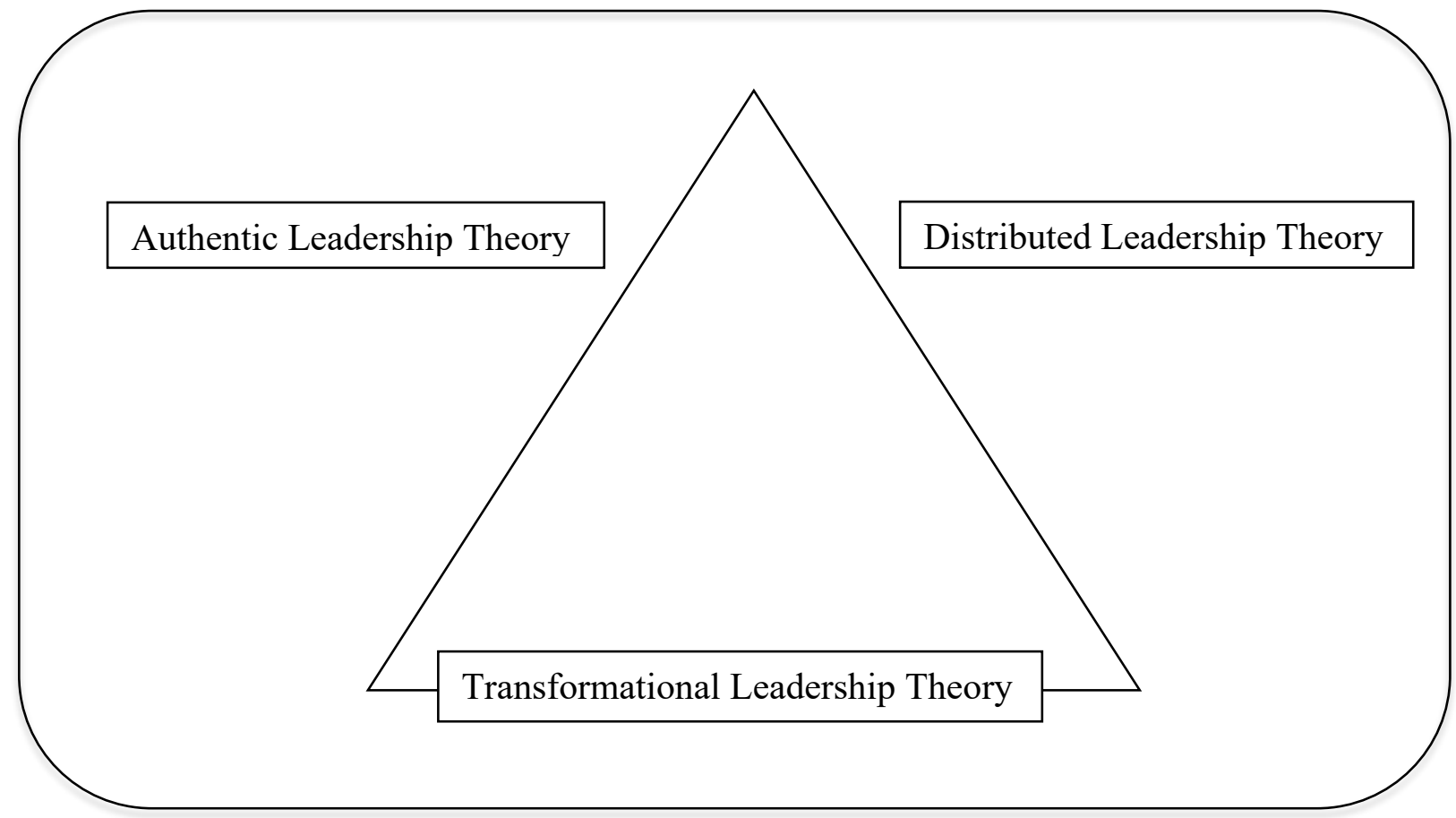

Klein (2016)

Transformational Leadership Theory

Defining Transformational Leadership

One of the most prevalent leadership theories researched over the past several decades is transformational leadership. Transformational leadership stems from the work of political scientists and sociologists and gained momentum as an approach to studying leadership when Burns (1978) introduced the term transforming leadership in. Transformational leadership is the process in which one person engages another and elevates the level of motivation and morality in both parties (Burns, 1978; Northouse, 2004). Burns argues by raising the conduct and ethical aspirations, both leaders and followers are transformed (1978). As such, the leader and the follower are connected and reliant on each other to raise performance. According to Burns, "power bases are linked not as counterweights but as mutual support for a common purpose" (p. 20). In turn, transformational leaders are able to identify the needs of followers by satisfying higher ethical and motivational needs in order to engage the whole individual (Burns, 1978). As such, transformational leaders can inspire, motivate, and encourage employees (and themselves) to achieve beyond expectations toward a common goal. Leaders and followers are also able to transcend to an optimal level of achievement based on the greater good of the organization.

According to Bass $(1985,1989)$, four tenants relate to transformational leadership: idealized influence/attributed charisma, inspirational motivation, intellectual stimulation, and individual consideration. Specifically, idealized influence/attributed charisma, defines the level of power, confidence, ideas the leader exudes, and sense of mission. This influence has a strong emotional appeal and can move followers from self-interest to focusing on the common good beyond a level of expectation. It also highlights leadership behaviors and alignment to vision, mission, and purpose, and is consistent with ethical 
and moral expectations. Inspirational motivation encourages followers to think beyond common expectations and motives to achieve at exceptional levels. Leadership has the ability to instill confidence in followers that the heightened level of achievement is achievable. Intellectual stimulation, encourages followers to challenge or question ideas, think innovatively, look for creative ways to solve problems, and ignites intellectual curiosity. Individual consideration allows leaders to identify strengths and needs in individual followers and encourage development, empowerment, and ultimately self-actualization (Walumbwa \& Wernsing, 2013).

\section{Research Findings}

Recent empirical studies in various fields and context have revealed mostly expected results. Chief Executive Officers (CEOs), who hold the top-leadership role within organizations, are commonly studied with relation to transformational leadership. A 2008 study conducted by Jung, $\mathrm{Wu}$, and Chow, used a sample of 50 Taiwanese telecommunication and electronics companies to explore how the CEO's transformational leadership abilities impacted innovation within the organization. The results demonstrated a direct and positive effect on the CEO's leadership style and level of innovation (Diaz-Saenz, 2011). In addition to senior leadership research, middle manager studies also reveal similar results. According to Singh and Krishnan, who studied the role of "altruism in the relationship between self-sacrifice" in India in 2008, transformational leadership positively related to follower's collective identity and perception of organizational performance (Diaz-Saenz, 2011, p. 303). In a military context, Eid, Johnsen, Bartone, and Nissestad (2008), explored the role of personal hardiness in initiating change or growth in a military training activity. Their study found a "significant increase in transformational and transactional leadership styles after the exercises" (as cited in Diaz-Saenz, 2001, p. 303). Additionally, it was discovered the transformational leadership style increased six months after the completion of the exercise.

Research conducted by Basham (2012), addresses the significance and broad appeal of transformational leadership in a higher education environment and specifically addresses a climate of change within an institution. With reduced government funding and the necessity to adapt to economic and organizational shifts, transformational leaders can instill a sense of encouragement and motivation for change.

\section{Application of Transformational Leadership Theory to the Role of Virtual Internship Leader}

When applying transformational leadership theory to the role, responsibilities, and 'best fit' characteristics of virtual internship leaders, identifying those who can drive and embrace higher order change is essential. Recognizing the need for change is transactional; institutions and companies that require a new direction, shift in organizational culture, or need to foster performance excellence, benefit from a transformational leader. Those leaders who demonstrate the ability to engage their constituencies beyond the transactional exchange relationship can heighten awareness of the need for fundamental, directional, and process changes (Bass, 1985). According to Bass, "This heightening of awareness requires a leader with vision, self-confidence, and inner strength to argue successfully for what he sees is right or good, not for what is popular or is acceptable according to the established wisdom of time" (p. 17). Transformational leaders can inspire, motivate, and captivate their followers and provide the direction necessary to enhance organizational performance. With an emphasis on intrinsic motivation and employee development placed in today's higher education environment and business environments, a charismatic and visionary leader can inspire constituencies, and in this case, internship students, to exceed performance even in a time of uncertainty (Northouse, 2013).

Both Burns and Bass address the prospect of ethical behavior as relative to leadership motives (Walumbwa \& Wernsing, 2013). Burns (1978) notes there is an ethical component inherently built into transformational leadership; however, Bass (1985) recognizes transformational leaders can use their abilities for good or bad intentions. The discussions that assess leadership ethics, values, and an overall moral compass, address the topic of authenticity and provide the platform for the emergence of authentic leadership theory. In a virtual internship context, transformational leaders can serve to inspire and motivate their interns as they navigate a virtual platform. 


\section{Authentic Leadership Theory}

Defining Authentic Leadership

Introduced initially by Luthans and Avolio (2003), authentic leadership theory merged concepts from positive organizational behavior, transformational/full-range leadership, and ethical leadership theories, to depict the type of leadership needed to survive and thrive in contemporary organizational environments. Defining authentic leadership is somewhat complex as scholars accept multiple interpretations or definitions of the term. Most widely accepted is the definition of authentic leadership from a developmental, rather than simply interpersonal, perspective. According to Northouse (2013), authentic leadership emphasizes the ability to demonstrate resiliency and ethical transparency, while engaging constituencies across all levels. Authentic leadership is viewed as something that can evolve within an individual and is developed over the lifetime of a leader's career. In organizations where change is imminent, the authentic leader can provide a foundation of trust and inspiration for followers.

According to Luthans and Avolio (2003), authentic leadership "draws from both positive psychological capacities and a highly developed organizational context, which results in both greater self-awareness and self-regulated positive behaviors on the part of leaders and associates, fostering positive self-development" (p. 243). A highly developed organizational context provides a clear organizational framework and culture of transparency. In those contexts, leaders and followers feel less vulnerable and are able to pursue the organization's vision, goals, and objectives. Authentic leaders are "confident, hopeful, optimistic, resilient, transparent, moral/ethical, future-oriented, and give priority to developing associates to be leaders" (p. 243). Additionally, authentic leaders can engage followers by demonstrating actions and behaviors that reflect their values (2003). Leadership can exhibit behaviors and model the way that followers can embrace and promote throughout an organization. They are guided beyond self-interest and operate from deeper values.

Building on this definition, Kernis (2003), who looks at authenticity and its relationship to optimal selfesteem, claims, "authenticity can be characterized as reflecting the unobstructed operation of one's true, or core self in one's daily enterprise" (p. 13). He argues authenticity has four key components which include awareness, unbiased processing, action, and relationship orientation (2003). Most authentic leadership models draw from the work of Kernis and part of his larger theory on self-esteem.

For the purpose of the virtual internship leader, the following tenants are identified as characteristic of authentic leaders: 1) transparency, present themselves as genuine and real - showing one's true self; fostering open communication and relationships with others in doing so 2) curiosity, includes a desire to learn, understand, and explore 3) vulnerability, which includes self-awareness of strengths, weakness, feelings, and can express these with others; also leads to compassion for others 4) openness, possessing the quality of being straightforward in actions and words 5) honesty, driven by honorable intentions and moral code. 6) trustworthiness, inspiriting trust and reliability 7) humility, displays humbleness and lack of ego in leadership role; leaders can be confident and humble at the same time, and 8) 'hot' relationships, which encourages the establishment of key relationships where individuals share genuine, real aspects of themselves to each other.

\section{Research Findings}

Although the previous decade has prompted an increase in authentic leadership discourse, surprisingly few empirical studies exist. The majority of research discussions focused on business environments and explored leadership behaviors and individual perceptions of those behaviors. Qualitative research conducted by George, Sims, McLean, \& Mayer (2007) explored how people become and remain authentic leaders. Researchers interviewed 125 leaders, primarily from business backgrounds (half were Chief Executive Officers) and nonprofit organizations. Participants were selected based on their reputations for authenticity. Results from the study did not uncover a consistent trait or characteristic from these leaders, but rather their authenticity evolved from their life stories and real-world experiences (2007). The limited research available also suggests, "leadership authenticity is in fact a relevant and potentially important issue for followers" (Caza \& Jackson, 2011, p. 356). With an ongoing interest in authentic leadership from the academic and business communities, the research environment is primed for more empirical studies relevant to various types of organizations. 


\section{Application of Authentic Leadership Theory to the Role of Virtual Internship Leader}

Leadership authenticity is relevant to the role, responsibilities, and characteristics of those responsible for managing virtual internship programs and students. Business leadership and executive development programs were the first to embrace the applicability of authentic leadership. With uncertain and challenging times across most industries, authentic leadership is relevant to organizations - including higher education - that need to foster meaningful relationships and genuinely relate with key constituencies (Avolio \& Gardner, 2005). This ongoing priority within higher education can provide followers with a "renewed focus on restoring confidence, hope, and optimism" (p. 316). As companies and higher education continue to compete for financial resources and the best talent, authentic leaders can open the doors to providing the organizational climate and environment for sustained success.

As financial and ethical scandals have surfaced throughout various industries over the past several decades - constituencies are demanding open and honest leadership (Northouse, 2013). Identifying those candidates who are trustworthy and genuine becomes a clear priority for selecting the best-fit leaders. Additionally, those serving in the role need to communicate and demonstrate authenticity and transparency through their actions. According to George (2003), authentic leaders must possess the following characteristics - passion, behavior, connectedness, consistency, and compassion. Not only should leaders possess these characteristics, but continually need to develop in each of those areas.

With the demands facing academic and business leaders in today's unpredictable economic climate, the need to exceed performance with numerous constituencies is necessary and can challenge the leader's personal authenticity (Bornstein, 2004). As leaders face new and complex challenges, the need to possess authentic leadership qualities will impact the success of their experience managing virtual internships.

Those virtual internship leaders who exhibit authentic leadership characteristics can model resiliency for their student interns and continue to inspire them during new or challenging times.

\section{Distributed Leadership Theory}

\section{Defining Distributed Leadership Theory}

Distributed leadership has gained prominence within educational management research throughout the past decade and acknowledges leading an organization involves multiple individuals who exert power or influence, transcending formal leadership roles (Spillane \& Diamond, 2007; Gosling, Bolden \& Petrov, 2009; Lumby, 2013). Occasionally referred to as shared leadership, shared governance, collaborative leadership, or democratic leadership, distributed leadership has taken a prominent hold on framing leadership research in complex organizational environments (Spillane \& Diamond, 2007). Distributed leadership tenants include: 1) collaboration, 2) open culture, 3) reflective practice, 4) leadership/ engagement at all levels, and 5) flexibility.

\section{Research Findings}

Leaders who serve in this role must quickly learn those aspects and adapt their leadership style accordingly. According to Gosling et al. (2009), "Distributed leadership is not a replacement for individual leadership, rather it is an essential complement that both facilitates, and is facilitated by, the leadership of specific individuals (p. 300). Virtual internship leaders who can engage and foster distributed leadership within their organizations have greater opportunities for succeeding in the role. According to research conducted by Jones et al. (2014), distributed leadership relies on endorsement and support from formal leadership. With a distributed leadership model, "achieving the engagement of a wider group of staff is more effective in implementing change, and...in a more complex world, the skills and expertise of more diverse people are necessary to create successful leadership" (Lumby, 2013, p. 583). The appeal of the distributed leadership model resides in today's desire for greater collaboration and collegiality, along with the need for collective input and leadership throughout institutions (Bolden, Petrov, \& Gosling, 2009).

\section{Application of Distributed Leadership Theory to the Role of Virtual Internship Leader}

Although transformational leadership theory and authentic leadership theory can provide frameworks for understanding the individual leadership characteristics of an academic or business professional 
managing virtual internships, using a distributed leadership perspective is also relevant and necessary as a means for predicting leadership and student success while engaged in the internship process. Distributed leadership notably aligns with educational leadership and organizational shared governance. Distributed leadership theory identifies that no "one individual" leader can be solely responsible for success in vast corporate or institutional contexts. Leaders who embrace distributed leadership characteristics can provide student interns with a sense of increased ownership in the internship and engagement in the process.

\section{Theoretical Framework Summary}

Framing the virtual internship through the Triangular Theoretical Leadership Model that includes transformational leadership theory, authentic leadership theory, and distributed leadership theory, can provide contemporary and practical knowledge for use to educate academic internship program leaders and business professionals responsible for supervising student interns and fostering a virtual environment that provides a valuable, growth-driven undergraduate experience.

\section{RECOMMENDATIONS}

As instructors of a virtual internship course, we had the opportunity to develop and hone our virtual skills and assess more broadly the impact that our virtual undergraduate HRD internship program beyond its current state. Based on this, we recommend that virtual internships are an excellent option for students and instructors that are seeking to:

- Engage in internships in other states and countries across the globe

- Embrace their virtual learning opportunities more actively

- Share their unique virtual learning experiences, with other students and instructors and

- Further develop the virtual internship curriculum

\section{CONCLUSIONS}

Though this experience as instructors of an undergraduate HRD virtual internship class, we affirm that virtual internships are a viable internship option that provides students with an opportunity to gain and enrich their relevant transferable skills. These transferable skills include but are not limited to adapting to learning virtually, being flexible and able to adjust well to new situations, working independently, meeting deadlines, proficiently utilizing virtual learning management platforms such as Zoom and WebEx, and effectively demonstrating confidence, time-management, communication skills, organizational skills, selfmotivation, multi-tasking, problem-solving skills, professional development, and maturity.

Virtual internships also provide academic instructors and supervisors an opportunity to collaboratively participate in a virtual learning experience while the Triangular Theoretical Approach is useful for guiding leadership behaviors. The virtual internship format also maximized time for all parties involved. We hope that this article will encourage academics and professionals in HRD and related fields to share their virtual internship teaching and learning experiences through scholarly journal articles for the purpose of building scholarly literature on this topic. 


\section{REFERENCES}

Avolio, B.J., \& Gardner, W.L. (2005). Authentic leadership development: Getting to the root of positive forms of leadership. The Leadership Quarterly, 16, 315-338.

Bashman, L.M. (2012). Transformational leadership characteristics necessary for today's leaders in higher education. Journal of International Education Research, 8(4), 343-348.

Bass, B.M. (1985). Leadership and performance beyond expectations. New York, NY: The Free Press.

Bass, B.M. (1989). Transformational leadership: Industrial, military, and educational impact. Mahwah, NJ: Lawrence Erlbaum Associates, Inc.

Bolden, R., Petrov, G., \& Gosling, J. (2009). Distributed leadership in higher education: Rhetoric and reality. Educational Management Administration \& Leadership, 37(2), 257-277.

Bornstein, R. (2004). The authentic, and effective, college president. The Chronicle of Higher Education, 50(47). Retrieved from http://chronicle.com.huaryu.kl.oakland.edu/article/TheAuthenticEffective/35426/

Burns, J.M. (1978). Leadership. New York, NY: Harper and Row Publishers, Inc.

Caza, A., \& Jackson, B. (2011). Authentic leadership. In A. Bryman, D. Collinson, K. Grint, B. Jackson, \& M. Uhl-Bien (Eds.), The Sage Handbook of Leadership (pp. 352-362). Thousand Oaks, CA: Sage Publications, Inc.

Diaz-Saenz, H.R. (2011). Transformational leadership. In A. Bryman, D. Collinson, K. Grint, B. Jackson, \& M. Uhl-Bien (Eds.), The Sage Handbook of Leadership (pp. 299-310). Thousand Oaks, CA: Sage Publications, Inc.

George, B., Sims, P., McLean, A., \& Mayer, D. (2007) Discovering your authentic leadership. Harvard Business Review, pp. 129-137.

Gosling, J., Bolden, R., \& Petrov, G. (2009). Distributed leadership in higher education: What does it accomplish? Leadership, 5(3), 299-310.

Jones, S., Harvey, M., Lefoe, G., \& Ryland, K. (2014). Synthesizing theory and practice: Distributed leadership in higher education. Educational Management Administration and Leadership, 42(5), 603-619.

Kernis, M.H. (2003). Toward a conceptualization of optimal self-esteem. Psychological Inquiry, 14(1), 126.

Klein, L.B. (2016). Understanding the experiences of non-traditional university leadership in higher education: A qualitative study using a triangular theoretical approach (Doctoral dissertation). Retrieved from ProQuest Dissertations and Theses database. (No. 10169336)

Lumby, J. (2013). Distributed leadership: The uses and abuses of power. Educational Management Administration and Leadership, 41(5), 581-597.

Luthans, F., \& Avolio, B.J. (2003). Authentic leadership development. In K.S. Cameron, J.E. Dutton \& R.E. Quinn (Eds.), Positive organizational scholarship: Foundations of a new discipline (pp. 241-258). San Francisco, CA: Berrett-Koehler Publishers, Inc.

Northouse, P.G. (2004). Leadership: Theory and practice (3rd ed.). Thousand Oaks, CA: Sage Publications, Inc.

Northouse, P.G. (2013). Leadership: Theory and practice (6th ed.). Thousand Oaks, CA: Sage Publications, Inc.

Spillane, J.P., \& Diamond, J.B. (2007). Distributed leadership in practice. New York, NY: Teachers College Press.

Walumbwa, F.O., \& Wernsing, T. (2013). From transactional and transformational leadership to authentic leadership. In M.G. Rumsey (Ed.), The Oxford handbook of leadership (pp. 392-400). New York, NY: Oxford University Press. 